The authors reported no conflicts of interest.

The Journal policy requires editors and reviewers to disclose conflicts of interest and to decline handling or reviewing manuscripts for which they may have a conflict of interest. The editors and reviewers of this article have no conflicts of interest.

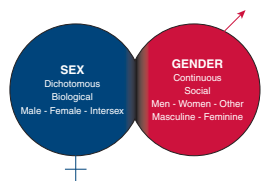

\section{DISSECTING SEX AND GENDER}

\section{To the Editor:}

With great interest, we read the study by Rylski and colleagues ${ }^{1}$ titled "Gender-Related Differences in Patients With Acute Aortic Dissection Type A," published recently in the Journal. The topic of male-female differences in aortic disease remains underexplored, despite the increasing attention for sex and gender differences in cardiovascular research. The paper is therefore very much welcomed, well-written, and provides insightful data. However, we have one critical comment regarding the use of the word "gender" by the authors to indicate the male-female cohorts.

Sex and gender are often used interchangeably by researchers; however, the terms indicate 2 different things. The World Health Organization defines "sex" as " ... the biological characteristics that define humans as female or male." " "Gender" is defined as "... the socially constructed characteristics of women and men-such as norms, roles and relationships of and between groups of women and men." research terms, sex is considered a binary variable. Gender, in contrast, is a continuous variable defined by the patient, including a range of characteristics varying with age, ethnicity, geographic location, education, and culture. ${ }^{4}$

In scientific research, it is very important to use uniform and correct definitions of key variables such as sex and gender to ensure that research on the topic is interchangeable. Furthermore, we must be mindful that often it remains unclear whether the observed effects or associations are attributable to sex, to gender, or to a combination of both. When this is the case, we suggest to use the term male-female differences to encompass the broader spectra of sex and gender.

\footnotetext{
The Editor welcomes submissions for possible publication in the Letters to the Editor section that consist of commentary on an article published in the Journal or other relevant issues. Authors should: • Include no more than 500 words of text, three authors, and five references. • Type with double-spacing. • See http://jtcs.ctsnetjournals.org/ misc/ifora.shtml for detailed submission instructions. • Submit the letter electronically via jtcvs.editorialmanager.com. Letters commenting on an article published in the JTCVS will be considered if they are received within 6 weeks of the time the article was published. Authors of the article being commented on will be given an opportunity of offer a timely response ( 2 weeks) to the letter. Authors of letters will be notified that the letter has been received. Unpublished letters cannot be returned.
}

In the study by Rylksi and colleagues, the terms male and man, and female and woman, were used interchangeably. This is not correct, as the terms refer to sex, respectively gender. We find male-female differences to be the more appropriate term to use in this paper, as the variables included in the investigation can be associated with both sex and gender. We encourage efforts such as those by performed by Rylksi and colleagues to increase the body of knowledge concerning this important topic, keeping in mind the correct nomenclature. It is important to explore determinants of adverse outcome in all genders, to improve the quality of care for all patients.

Arjen L. Gökalp, $M D^{a}$

Carlijn G. E. Thijssen, $M D^{b}$

Jolien W. Roos-Hesselink, $M D, P h D^{b}$

Johanna J. M. Takkenberg, MD, PhD

Departments of ${ }^{a}$ Cardiothoracic Surgery

${ }^{b}$ Cardiology

Erasmus University Medical Center Rotterdam, The Netherlands

Funding statement: This work was supported by the Dutch scientific funding agency ZonMw

(Project number 849200014).

Drs Gökalp and Thijssen contributed equally to this letter.

\section{References}

1. Rylski B, Georgieva N, Beyersdorf F, Büsch C, Boening A, Haunschild J, et al Gender-related differences in patients with acute aortic dissection type A. J Thorac Cardiovasc Surg. November 27, 2019 [Epub ahead of print].

2. WHO. World Health Organization Working Definition of "Sex". Available at: https://www.who.int/reproductivehealth/topics/gender_rights/sexual_health/en/. Accessed March 21, 2020.

3. WHO. World Health Organization Definition of "Gender". Available at: https:// www.who.int/gender-equity-rights/understanding/gender-definition/en/. Accessed March 21, 2020.

4. CIHR. Canadian Institutes of Health Research. "The Ethical Imperative of Sex and Gender Considerations in Health Research”. Available at: https://cihr-irsc.gc.ca/e/ 49932.html. Accessed March 21, 2020.

https://doi.org/10.1016/j.jtcvs.2020.03.148

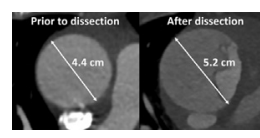

REPLY FROM

AUTHORS: SEMANTICS AGAINST IMPROVING OUTCOME OF TYPE A DISSECTION SURGERY: WE CAN WIN THE BATTLE, BUT HOW NOT TO LOSE THE WAR?

\section{Reply to the Editor:}

It was with great interest that we read the Letter to the Editor by Gökalp and colleagues titled "Dissecting Sex and Gender" commenting on our paper "Gender-Related Differences in Patients With Acute Aortic Dissection Type A." ${ }^{2}$ We appreciate the sincere, deep concerns of 